\title{
Tube feeding: Intestinal factors in gastric loading
} SAUL BALAGURA, UNIVERSITY OF CHICAGO
HANS C. FIBIGER, PRINCETON UNIVERSITY
An experiment was performed to measure stomach retention as a function of stomach load in 60 female albino rats. Each group $(N=10)$ was loaded with 5,12 , or $25 \mathrm{ml}$ of either isotonic saline or Metrecal. It was found that stomach retention was equal to stomach load only in the $5 \mathrm{ml}$ condition. When greater loads were used, an increasing proportion of the loads passed into the intestine. Intestinal factors in the short term regulation of eating are stressed.

The gastric catheter and fistula techniques of stomach loading have been widely used in the study of food intake regulation (Kohn, 1951; Miller \& Kessen, 1952; Berkun, Kessen, \& Miller, 1952; Smith \& Duffy, 1955). The typical experimental paradigm consists of a stomach loading session using a gastric catheter or fistula, and a subsequent test session to observe the effect on such variables as food intake, water intake, bar pressing for food or water. The main conclusions drawn by these authors have been discussed partly in terms of gastric factors and are based on loadings ranging from 5 to $14 \mathrm{ml}$.

The present experiment demonstrates that experimental results based on stomach loads (in rats) of more than $5 \mathrm{ml}$ can not be explained only in terms of stomach effects such as distention, osmosis, or neurohumors, but must also consider intestinal factors. Method

Sixty female Sprague-Dawley rats were divided into six groups $(\mathrm{N}=10)$ approximately equated for weight (range $312-329 \mathrm{~g}$ ). After $4 \mathrm{~h}$ of food and water deprivation, the Ss were anesthetized (sodium Nembutal $0.035 \mathrm{mg} / \mathrm{g}$ ) and a Nelaton catheter $(8 \mathrm{Fr}$ ) was inserted through the mouth into the stomach. Following an abdominal incision, a silk cord was knotted firmly around the esophagus, sparing the vagus nerves, to seal the esophagus to the catheter and thus prevent load regurgitation. Each group was stomach loaded with 5,12 , or $25 \mathrm{ml}$ of either isotonic saline or liquid Metrecal, at a rate of $10 \mathrm{ml} / \mathrm{min}$. Upon termination of loading the stomach was immediately clamped at the pyloric level. The stomach was then removed and its liquid content was measured. A clamp was also placed at the point to which the fluid had travelled along the intestine, and the distance between the pyloric and intestinal clamps was recorded. This was taken as a measure of intestinal distention.

\section{Resulis}

Figure 1 shows mean stomach retention and intestinal distention as functions of stomach load. Analysis of variance revealed that the illustrated functional relations are statistically significant $(p<0.01)$. As may be seen from the figure, stomach retention was also found to vary with the type of solution administered $(\mathrm{p}<0.05)$.

The results clearly demonstrate that stomach retention was equal to stomach load only under the $5 \mathrm{ml}$ condition. With increasing gastric loads the stomach was found to retain a diminishing proportion of the loads. Administration of $12 \mathrm{ml}$ distended the intestine to the level of the middle jejunum, while $25 \mathrm{ml}$ resulted in distention to the level of the ileocecal region. Passage of gastric contents into the duodenum, associated with peristalsis, was observed when an average of $3 \mathrm{ml}$ had been injected into the stomach.

\section{Discussion}

Evidence for several factors has been adduced to account for the satiation of hunger. Janowitz (Janowitz \& Grossman, 1949) measured the effects of oral feeding and stomach loading on subsequent food intake on dogs. It was found that equal weights of both food and calorically inert material administered by stomach fistula, depressed subsequent food intake. The authors concluded that cessation of eating was due to mechanical effect of stomach distention. They also found that oral factors alone could cause cessation of eating. Gastric factors were operative only when in close association with oral ingestion in esophagostomized dogs. When stomach balloons were used it is noteworthy that inhibition of sham feeding did not occur until 900 to $1000 \mathrm{ml}$ of air, at a pressure of $4 \mathrm{~cm}$ of mercury, were introduced into the balloon. In a later study (Share, Martyniuk, \& Grossman, 1952), results indicated that an inverse relationship exists between amount of stomach loading and subsequent oral intake.

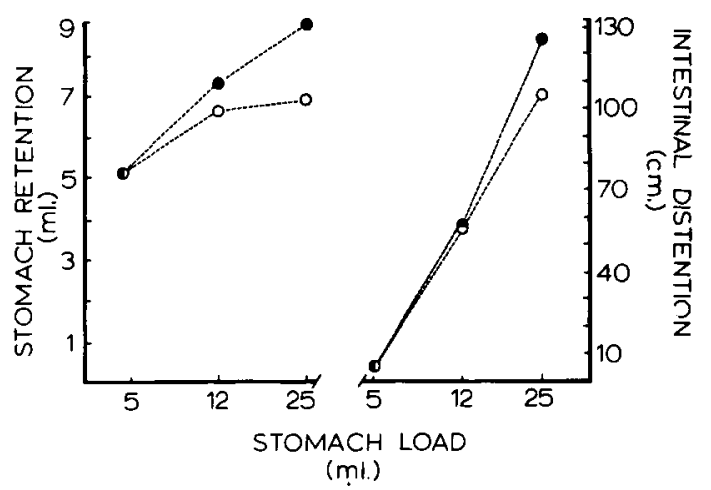

Fig. 1. Stomach retention and intestinal distention as functions of stomach load-Empty circles: isotonic saline load; dark circles: Metrecal load. 
Other experiments have investigated the effects of gastric loadings on rats. Kohn (1951) demonstrated a decrease in instrumental responding for food after a stomach load of $14 \mathrm{ml}$ of milk. No significant difference in operant responding for food was found between a saline loaded group and unloaded controls. Kohn concluded that food placed in the stomach brought about a reduction in hunger, but that it was highly improbable that digestion and absorption of the food played a significant role in producing this effect.

Berkun, Kessen, \& Miller (1952) using a consummatory response as a measure of hunger obtained results consonant with those of Kohn (1951). Intragastric injection of $14 \mathrm{ml}$ of milk decreased the amount of food subsequently ingested during a test period more than did an equal volume of isotonic saline. In agreement with Kohn, these authors also stated that it was exceedingly unlikely that the results were due to the effects of digestion and absorption of the load.

Smith \& Duffy (1955) showed that whereas stomach loading of $10 \mathrm{ml}$ of isotonic saline had no effect upon bar pressing for food, loads of $30 \%$ sucrose depressed instrumental responding. Three load volumes of sucrose were used $(4,7$, and $10 \mathrm{ml})$, and a direct relationship was observed between size of stomach load and degree of inhibition of operant responding for food. In a later study, Smith \& Duffy (1957) showed that gastric loads of $10 \mathrm{ml}$ or more of an inert material (Kaolin) depressed eating, while a $5 \mathrm{ml}$ load had no effect. They concluded that intragastric bulk is an important factor in the control of eating.

The present experiment has certain implications for experiments that utilize gastric loading techniques. In all the above cited studies, there was a considerable delay ( 7.5 to $18 \mathrm{~min}$ ) between initiation of loading and the beginning of the test period. Many of the authors specifically rejected absorptive and digestive factors as important influences in the control of eating shortly after ingestion. They have implied that most of the fluid remains in the stomach, where absorption is greatly limited, and that very little fluid reaches the intestine where significant absorption can take place. Our observations indicate that intestinal filling begins after gastric loads exceed $3 \mathrm{ml}$, and it may be assumed that either mechanical, osmotic, or digestive processes can commence as soon as this event occurs.

It could be argued that a barbiturate anesthesia might have contaminated the present results. However, experiments measuring stomach retention under the influence of these compounds demonstrate that the rate of gastric emptying decreases (Goodman \& Gilman, 1965). Barbiturates would thus increase stomach retention.

In conclusion, it seems likely that intestinal factors play a more significant role in the short term regulation of eating than past research has indicated. It is suggested that experiments that utilize stomach loads exceeding $5 \mathrm{ml}$ should not disregard the contribution of the intestine in the control of food intake.

\section{References}

BERKUN, M. M., KESSEN, M. L., \& MILLER, N. E. Hunger-reducing effects of food by stomach fistula versus food by mouth measured by a consummatory response. J. comp. physiol. Psychol., 1952, $45,550-554$.

GOODMAN, L. S., \& GILMAN, A. The pharmacological basis of therapeutics. New York: The Macmillan Co., 1965.

JANOWITZ, H. D., \& GROSSMAN, M. I. Some factors affecting the food intake of normal dogs and dogs with esophagostomy and gastric fistula. Am. J. Physiol, 1949, 159, 143-148.

KOHN, M. Satiation of hunger from food injected directly into the stomach versus food ingested by mouth. J. comp. physiol Psychol, $1951,44,412422$.

MILLER, N. E., \& KESSEN, M. L. Reward effects of food via stomach fistula compared with those of food via mouth. J. comp. physiol. Psychol., 1952, 45, 555-564.

SHARE, I., MARTYNIUK, E., \& GROSSMAN, M. I. Effect of prolonged intragastric feeding on oral food intake in dogs. Amer. J. Physiol, 1955, 48, 387-391.

SMITH, M., \& DUFFY, M. The effects of intragastric injection of various substances on subsequent bar-pressing. J. comp. physiol. Psychol., 1955, 48, 387-391. 